\title{
RELEVANCE OF SECONDARY PROCESSES IN ORAC VALUES OBTAINED EMPLOYING PYROGALLOL RED AS TARGET MOLECULE
}

\author{
C. LÓPEZ-ALARCÓN, ${ }^{1^{*}}$ A. ASPEÉ, ${ }^{2}$ AND E.A.LISSI ${ }^{2}$

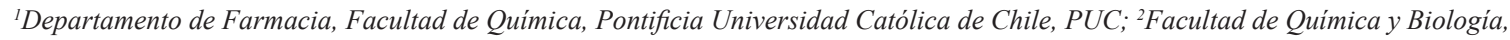 \\ Universidad de Santiago de Chile, USACH. \\ Departamento de Farmacia, Facultad de Química, Pontificia Universidad Católica de Chile. Av. Vicuña Mackenna 4860, Macul, Santiago. P.C.: 7820436. \\ Phone: 56-2-3544838. Fax: 56-2-6864744
}

(Received 18 January 2008 - Accepted 5 August 2008)

\begin{abstract}
Pyrogallol red (PGR) is readily bleached by peroxyl radicals. Addition of cinnamic acid derivatives (coumaric, caffeic, ferulic and sinapic acids), even at relatively high concentrations, barely protects PGR from bleaching, given very low ORAC (oxygen radical absorbance capacity) values. This lack of protection is contrary to that expected from the relative reactivity of cinnamic acid derivatives and PGR. It is concluded that the protection is not determined by competition of the antioxidant and the target molecule for peroxyl radicals, but for secondary processes involving phenoxyl and PGR derived radicals. In particular, the occurrence of processes such as

$\mathrm{PO}+\mathrm{PGR} \rightarrow \mathrm{POH}+\mathrm{PGR} \cdot$
\end{abstract}

can explain the lack of PGR protection even in conditions where most of the peroxyl radicals are trapped by the additive.

Keywords: ORAC; pyrogallol red, secondary reactions; cinnamic acid derivatives.

\section{INTRODUCTION}

Evaluation of the antioxidant activities in complex mixtures (foods, juices and beverages) is a matter of current interest, and several methodologies have been proposed to fulfill this aim. ${ }^{1}$ Among these methodologies, ORAC (oxygen radical absorbance capacity) is one of the most popular procedures currently employed to quantify antioxidants capability, employing fluorescein as target molecule. ${ }^{2}$ However, inhibition of fluorescein consumption by most antioxidants generates neat induction times and hence the integration of the area under the curve renders ORAC values that are only determined by stoichiometric factors, irrespective of the tested substrate reactivity towards peroxyl radicals. This remarkable protection has been related to secondary reactions involving fluorescein $(\mathrm{FlH})$ and substrate $(\mathrm{POH})$ derived radicals: ${ }^{3}$

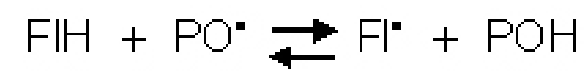

If this equilibrium is displaced towards the left and the main radical consuming step is the process (2)

$$
\mathrm{PO}^{\cdot}+\mathrm{PO}^{\cdot} \rightarrow \text { products }
$$

FlH will be totally protected by $\mathrm{POH}$ addition, even if a significant fraction of the primary peroxyl radicals reacts with the dye. A similar mechanism has been proposed to explain results obtained employing pyranine as target molecule. ${ }^{4}$

In a previous work we have proposed an ORAC-type methodology employing pyrogallol red (PGR) as target molecule. ${ }^{5}$ In this system, only very reactive phenols were able to protect PGR, and the protection was evidenced as a reduction of its bleaching rate, without the appearance of induction times. This behavior was explained in terms of a competition between the probe (PGR) and the added phenols for peroxyl radicals, rendering so ORAC values determined by the reactivity of the tested phenol. In the present work, we present quantitative results that would indicate that the lack of PGR protection by cinnamic acid derivatives is mostly due to secondary damage brought by phenoxyl radicals. Similar processes have been proposed to be relevant when c-phycocianin is employed as target molecule. . $^{6-9}$

\section{EXPERIMENTAL}

Chemicals.

2,2'-Azo-bis(2-amidinopropane) dihydrochloride, (AAPH), was used as peroxyl radical source. Pyrogallol red (PGR), all tested cinnamic acid derivatives, and AAPH were purchased from Sigma-Aldrich (St. Louis, MO) and employed as received.

Solutions.

Stock solutions of the cinnamic acid derivatives were prepared in ethanol immediately before their use. Stock solutions of PGR $\left(1 \times 10^{-4} \mathrm{M}\right)$ were prepared daily in phosphate buffer $75 \mathrm{mM}, \mathrm{pH}$ 7.4. A reaction mixture containing AAPH $(10 \mathrm{mM})$, PGR $(5 \mu \mathrm{M})$ with or without the tested cinnamic acid derivatives in phosphate buffer $(75 \mathrm{mM})$ at $\mathrm{pH} 7.4$, was incubated at $37^{\circ} \mathrm{C}$ in the thermostatized cuvette of a Hewlett Packard 8453 (Palo Alto, CA, USA) UV-visible spectrophotometer. PGR consumption was evaluated from the progressive absorbance decrease measure at $540 \mathrm{~nm}$. Cinnamic acids consumption was estimated from parallel experiments. ${ }^{10}$ Briefly, cinnamic acids were incubated at $37^{\circ}$ in presence of $10 \mathrm{mM}$ of AAPH in phosphate buffer $(10 \mathrm{mM}), \mathrm{pH} 7.0$, under aerobic conditions. At different times, aliquots were taken and immediately injected in the high performance liquid chromatography (HPLC) system. ${ }^{10}$ The $\mathrm{k}_{4} / \mathrm{k}_{3}$ values were estimated from initial consumption rate versus antioxidant concentration plots. ${ }^{10-11}$

\section{RESULTS AND DISCUSSION}

If it is assumed that the protection afforded by an additive to PGR bleaching is due to competitive trapping of the originally produced peroxyl radicals, its efficiency will depend upon the relative values of the rate constants of processes (3) and (4)

and

$$
\mathrm{ROO}^{*}+\mathrm{PGR} \rightarrow \mathrm{PGR}^{*}+\mathrm{ROOH}
$$

$$
\mathrm{ROO}^{*}+\mathrm{POH} \rightarrow \mathrm{PO}^{*}+\mathrm{ROOH}
$$

that can involve, as rate determining step, an hydrogen and/or electron transfer. In this case, if $\mathrm{R}^{\circ}$ is the rate of PGR consumption in absence of $\mathrm{POH}$, it can be shown that, when most of the peroxyl radicals are trapped by PGR and/or $\mathrm{POH}$

$$
\frac{\mathrm{P}^{0}}{\mathrm{R}}=1+\frac{\mathrm{k}_{4}}{\mathrm{k}_{3}} \frac{[\mathrm{POH}]}{[\mathrm{PGR}]}
$$

Eqn. (5) shows that $R \% R$ values can be predicted if $k_{/} / k_{3}$ is known. This ratio can be estimated from parallel experiments in which it is measured the rate of consumption of PGR or POH as a function of its concentration. ${ }^{10,11}$ These type of data have been obtained for PGR and the cinnamic acid derivatives, and the corresponding $\mathrm{k}_{4} / \mathrm{k}_{3}$ values collected in Table $\mathbf{1}$. 
Eqn. (5) can then be applied to predict $\mathrm{R} \% \mathrm{R}$ values as a function of $[\mathrm{POH}] /$ [PGR]. These data treatment is shown in Fig. 1. In this figure $\mathrm{R}^{\circ} / \mathrm{R}$ values directly determined from competitive experiments are also included. ${ }^{5}$ It is clear that the $\mathrm{R}^{\circ} / \mathrm{R}$ values obtained by this procedure are significantly smaller than those predicted from $\mathrm{k}_{4} / \mathrm{k}_{3}$ values. This implies that PGR is considerably less protected by the $\mathrm{POH}$ than could be expected from their relative reactivity. Furthermore, the protection afforded by a given $\mathrm{POH}$ does not directly correlate with its reactivity towards peroxyl radicals. In particular, the data of Table $\mathbf{1}$ show that, even when caffeic acid is less reactive, it affords a considerably larger protection than that of ferulic acid. All this would indicate that the protection afforded to PGR, and hence the ORAC-PGR value, is not directly related to the reactivity of the tested compound towards the azo-derived peroxyl radicals.

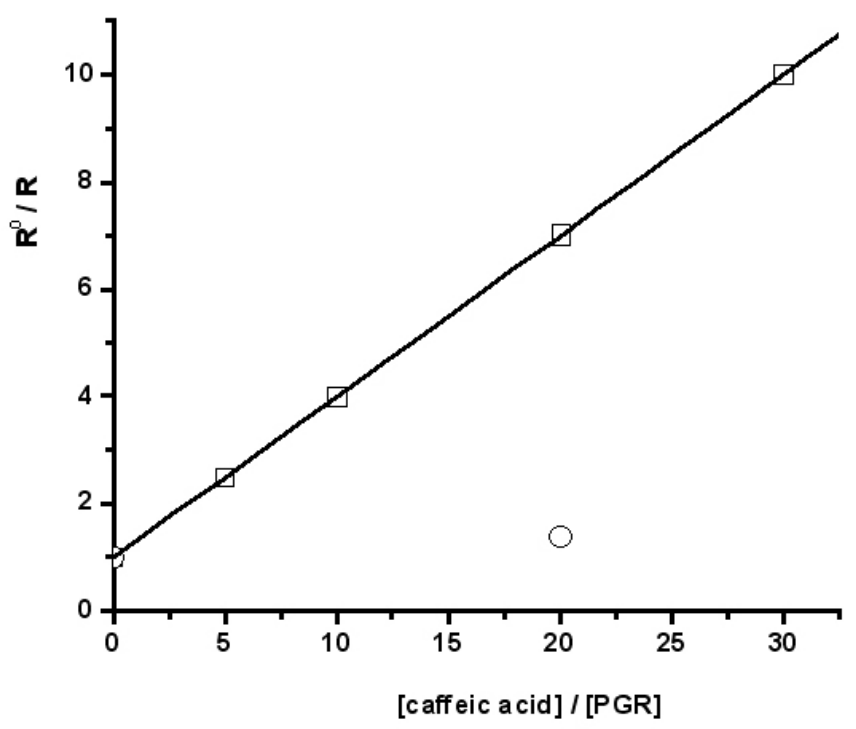

Figure 1. Ratio between the initial rate of PGR consumption in the absence $\left(\mathrm{R}^{0}\right)$ and presence $(\mathrm{R})$ of caffeic acid. $(\mathrm{O})$ Values calculated with $\left(\mathrm{k}_{\mathrm{cafec}} / \mathrm{k}_{\mathrm{PGR}}\right)=$ 0.3. ( $\bigcirc)$ Value experimentally determined in competitive experiments.

Table 1. Experimentally determined (exp) and calculated (t) $R^{\circ} / R$ values.

$\begin{array}{ccccc}\text { Compound } & \mathbf{k}_{4} / \mathbf{k}_{3}^{*} & \begin{array}{c}{[\mathrm{POH}]} \\ \text { Micromolar }\end{array} & \mathbf{R}^{0} / \mathbf{R}_{\mathrm{t}} & \mathbf{R}^{0} / \mathbf{R}_{\text {exp }} \\ \text { Caffeic acid } & 0.3 & 100 & 7.0 & 1.4 \\ \text { Sinapic acid } & 0.5 & 100 & 11 & 1.4 \\ \text { Ferulic acid } & 0.7 & 500 & 71 & \leq 0.8 \\ \text { Coumaric acid } & 0.1 & 500 & 11 & \approx 1.0\end{array}$

$\mathrm{R}^{\mathrm{o}} / \mathrm{R}(\mathrm{t})$ values were calculated employing Eqn $(5) .{ }^{*} \mathrm{k}_{4} / \mathrm{k}_{3}$ values were derived from published data. ${ }^{10,11}$

Lack of PGR protection can be due to secondary damage elicited by POH derived radicals. In particular, the occurrence of reaction

$$
\mathrm{PO}^{\bullet}+\mathrm{PGR} \rightarrow \mathrm{PGR} \text { bleaching }
$$

can lead to PGR consumption even under conditions such that most of the peroxyl radicals are trapped by the added phenol. This reaction would be favoured by the relatively high reactivity of phenol derived radicals and, in the limit, can involve equilibration of phenol and PGR derived radicals:

\section{$\mathrm{PO}^{*}+\mathrm{PGR} \rightleftarrows \mathrm{POH}+\mathrm{PGR}^{*}$}

The relevance of reaction (6) would depend on:

i) the reactivity of $\mathrm{PO}^{*}$ and or the position of equilibrium (7). This could be directly related to the strength of the $\mathrm{POH}$ bond and/or to the electron affinity of the radical. ${ }^{8}$ This would explain why process (6) is less relevant for sinapic acid.

ii) The rate constant of process (2) $(\mathrm{PO} \bullet+\mathrm{PO} \bullet$ processes). If these processes are very rapid, reaction (6), would be less important and hence PGR consumption will not be quantitative. Processes involving two phenoxyl radicals can be particularly fast when they lead to the formation of quinones. ${ }^{10}$ This could explain why caffeic acid is more efficient than ferulic acid in the protection of PGR (Table 1).

\section{CONCLUSIONS}

ORAC-PGR values of cinnamic acid derivatives are considerably smaller than those predicted from their reactivity towards peroxyl radicals. This lack of protection can be interpreted in terms of secondary reactions, in which cinnamic acid derived radicals react with PGR.

\section{ACKNOWLEDGMENTS}

This work was supported by FONDECYT (Projects n 11060323,1085177 , and 1070285)

\section{REFERENCES}

1. V. Roginsky, E. Lissi, Food Chem., 92, 235, (2005).

2. B. Ou, M. Hampsch-Woodill, R.L. Prior, J. Agric. Food Chem., 49, 4619, (2001).

3. R.H. Bisby, R. Brooke, S. Navartman, Food Chem., 108, 1002, (2008).

4. A.M. Campos, C.P. Sotomayor, E. Pino, E. Lissi, Biol. Res., 37, 287, (2004).

5. C. López-Alarcón, E. Lissi, Free Radic. Res., 40, 979, (2006).

6. E. Pino, E. Lissi, Helv. Chim. Acta., 84, 3677, (2001).

7. E. Pino, A. Aspé, C. López-Alarcón, E. Lissi, J. Phys. Org. Chem., 19, 867, (2006)

8. E. Pino, A.M. Campos, C. López-Alarcón, A. Aspée, E. Lissi, J. Phys. Org. Chem., 19, 759, (2006).

9. C. López-Alarcón, A. Aspée, E. Lissi, Food Chem., 104, 1430, (2007).

10. C. López-Alarcón, A. Aspée, E. Lissi, Free Radic. Res., 41, 1189, (2007).

11 C. López-Alarcón, E. Lissi, Free Radic. Res., 39, 729, (2005). 